\title{
Child and adolescent injury control activities: reports from the field
}

This year at the meeting of the International Society for Child and Adolescent Injury Control (ISCAIP) after the Third World Conference on Injury Prevention and Control in Melbourne, we had presentations outlining injury control activities from the different regions of the world. These reports are summarized here.

\section{Europe (provided by Ian Roberts, Institute for Child} Health, UK)

There are 18 countries in the European Economic Area (EEA). In an attempt to obtain as wide a European perspective as possible the following strategies were used: (1) letters were sent to all European members of the editorial board of Injury Prevention, (2) the ISCAIP membership database was searched for any European members, who were then contacted, (3) letters were sent to individuals and organizations with a key role in injury prevention in Europe, and (4) publications that specifically addressed the injury control problem from a European perspective were reviewed.

There are large international differences in child injury mortality rates in Europe. According to WHO statistics, Portugal has the highest child injury mortality rate and Italy the lowest. ${ }^{1}$ If the links with government policies could be identified, these international differences may provide important insights into injury causation. However, differences in injury mortality rates across Europe may simply reflect diversity in national procedure for reporting and classifying injury deaths. Several of the European respondents pointed out that the standardization of injury data collection is a major challenge for injury control in Europe. This would involve standardization of both mortality and hospital morbidity data collection.

Harmonization of safety regulations and standards across the EEA provides an opportunity for injury control in Europe. Although trade interest is the predominant objective, the need to harmonize national regulations and standards towards a common European standard has been, and remains, an important vehicle for establishing standards at an optimum level. Although the European Commission also has a mandate to improve the living conditions of European citizens and to safeguard their health and safety, as yet, there are few clear policy initiatives in this area.

Several of the European respondents pointed to the continued decline in child injury mortality as a success of injury control. In France, there has been a $45 \%$ decline in child injury mortality over the past decade. Significant reductions have also been noted in Sweden, Greece, and the UK. However, the extent to which these declines are due to injury prevention efforts, as opposed to changed in case fatality or gradual changes in exposure patterns remains unknown.

There is encouraging evidence that child injury control is increasingly taking a more prominent position on political agendas in Europe. In Greece, injuries have been acknowledged in the first formal health plan, and in the UK the Health of the Nation has established the reduction of child injury death rates as a national priority. There are an increasing number of European organizations with a key role in child injury control, such as APSI in Portugal and the Austrian Committee for Child Injury Control. While injury research in Europe has traditionally lagged behind North American research activity, this may be changing. For example, in 1991 a Center for Research and Prevention of Injuries among the Young was opened in Greece.

Most European respondents felt that injuries to adolescents were a major but neglected challenge, especially road traffic accidents. Although injury death rates are highest in the teens, there is a paucity of high quality injury research relevant to this age group. This may stem from a belief that the prevention of injuries to vehicle occupants is primarily the responsibility of transportation departments. This view deserves to be challenged.

Africa (provided by David Bass, Child Accident Prevention Foundation of Southern Africa, South Africa)

African children have reaped the dubious benefits of colonialism, civil war, poverty, and drought. Standards of health care on the African continent are variable but generally poor by Western standards. In many countries, health budgets are non-existent, having been plundered by the costs of war or bankruptcy. The high prevalence of malnutrition and infectious diseases as well as persistently high infant motality have ensured that child safety (in the Western sense) remains low on the list of health priorities.

African data on injuries are scarce, but patterns and distribution of such injuries appear to be similar to those described in developed countries. Unfortunately, virtually all African data on injuries is derived from hospital records and population based incidence estimates are unlikely to be accurate. It is likely that accurate compilation of injury data will remain a near impossible task until formal health systems are established throughout the continent, but lack of such data does not mean that safety programs themselves need to be put on hold indefinitely. The real dilemma is how to design and to execute such programs. Traditional 'Western' approaches that assume a high level of health awareness, near universal literacy, and the rule of law are not going to succeed in Africa. Child safety needs to be promoted on the terms of people who already have more than enough hardship with which to contend, and herein lies the challenge.

Asia (provided by R Krishnan, University of Malaya, Malaysia and Myint Myint Thein, University of Singapore, Singapore)

Asia is a continent of many races, religions, and cultures. Any account of health problems in Asia must take into account this great diversity. With the reduction of many infectious diseases, childhood injuries have become a leading cause.of mortality and morbidity. Injuries account for approximately $9 \%$ of disability adjusted life years (DALY) lost in India in 1990, 17\% in China, $11 \%$ in the 
rest of Asia, and $12 \%$ worldwide. $^{2}$ Children under 15 account for approximately one half of this total in India and China, and one third in the rest of Asia.

The two leading causes of fatal childhood injuries in selected countries are - Hong Kong: road, intentional; India (rural): road, burns; Japan: road, drowning; Malaysia: road, home; Myanmar: home, drowning; Philippines: drowning, road; Singapore: falls from height, road; and Taiwan: road, drowning. (Source: Precongress Workshop on Childhood Injuries; Seventeenth Asian Congress of Pediatrics, Perth 1991.)

Children are increasingly injured on the road as motorcycle passengers, pedestrians, cyclists, and vehicle occupants. Young children are transported as passengers on motorcycles by lower and middle income families. An effective public transportation system would decrease exposure to this risk. Child restraints and bicycle helmets are expensive; they should be made more affordable by local manufacturers and exempt from import tax. Adequate pedestrian facilities especially near school are urgently required. Drowning is a problem in countries with wide coastal areas. In urban areas high rise homes are a norm and prevention of falls is a priority. Many developing countries in Asia are in transition and need to learn from the lessons of other developed countries.

\section{North America (Susan Gallagher, Children's Safety Network, US)}

It is a major challenge to compile an overview of some of the many innovative child injury prevention activities that are occurring in Canada and the US. I ask that you not be offended if I have excluded something of importance, but instead, send your update in writing to the editor of Injury Prevention; this will insure that it is included in a future issue of the journal.

\section{IMPROVEMENT IN INJURY DATA SOURCES AND} DISSEMINATION

Health US, an annual report and chart book, will feature injuries as the focus for its 1996 edition. The US National Health Interview Survey has been redesigned to include a core group of questions on injury annually and a provision for an E-code for each injury that is reported. A more extensive supplementary set of injury questions will be asked every few years. The US National Ambulatory Health Care Survey is being analyzed to produce a special report on children's injuries. In February 1996, another edition of Childhood Injury State by State Mortality Facts was published and expanded to encompass injuries for those ages $0-19$ years for a seven year period $(1986-92){ }^{3}$

\section{A SAMPLING OF MILESTONES IN THE US}

- A version of the safe communities concept has been embraced by the National Highway Traffic Safety Administration. It is being heavily promoted by this agency with communities anxiously awaiting to see if new resources will be forthcoming for this initiative.

- The Emergency Medical Services for Children program of the federal Maternal and Child Health Bureau has become an $\$ 11$ million dollar program that is encompassing prevention and child injury prevention projects initiated by emergency medical staff. It also has a heavy emphasis on solving problems in rural areas.

- The National Committee for Childhood Agricultural Injury Prevention has released their national action plan. Thirteen objectives and 43 recommended action steps have been proposed. Consensus among federal agencies has led to an agreement that the National Institute of Occupational Safety and Health assume leadership for coordinating such efforts.

In its eighth year, the National SAFE KIDS Campaign continues to be a motivating force for many communities and public policy efforts with nearly 200 affiliates in 50 states. For the first time the National Institute of Occupational Safety and Health is funding community based, pilot projects at three sites to reduce injuries to teens in the workforce. Traditionally, they have not funded community programs, nor emphasized adolescents. The childhood initiatives from the National Center for Injury Prevention and Control of the Centers for Disease Control (CDC) continue to emphasize the prevention of youth violence from a public health perspective. With the summer Olympics scheduled in Atlanta, CDC is also focusing on surveillance of injuries among athletes and spectators.

- The National Collaboration, a consortium of foundations who have pooled their resources, is funding 12 US communities to deal with youth violence with outside technical assistance and evaluation expertise provided.

\section{A SAMPLING OF MILESTONES IN CANADA}

Ontario passed Canada's first bike helmet laws for youth under age 18 and two other provinces (British Columbia, Saskatchewan) are close to finalizing similar laws.

- The Canadian Parliament has approved a bill requiring registration of $A L L$ firearms (including rifles) by the year 2001. Prime Minister Jean Chretien was quoted: 'The bill gives us a personality different from the people of the south of us, and I am very proud'. It certainly creates envy in the US.

- SAFE KIDS Canada is entering its fourth year and now has 24 affiliates across Canada that currently focus on car seat safety, bike safety, and playground safety.

- The CHIRPP injury database now has 350000 records with 10 pediatric hospitals and five general hospitals participating on a voluntary basis.

\section{SETBACKS AND CHALLENGES}

The US Congress has repealed the 55/65 miles per hour speed limit and removed the provision to withhold federal highway money from non-compliant states. The result many state legislatures are passing laws to increase speed limits. The effect on children's injuries needs to be monitored.

Changes in health care policy in the US to capitated, prepaid system may result in more emphasis placed on prevention as a way of controlling health care costs. The potential benefit to injury prevention is enormous; it remains to be seen whether this potential will become a meaningful reality.

Other challenges in North America include increasing the amount of attention to adolescent injuries, as well as certain injury topics such as sports and leisure, suicide and handguns, and child labor in the workforce. Finally, the unmet needs for continuing education on injury prevention topics and methods for implementing and evaluating childhood injury prevention programs continue. Tragically, leadership in this area does not appear to be forthcoming.

\section{Australia and New Zealand (provided by Ian Scott)} AUSTRALIA

Despite substantial success in introducing injury control measures there is little secure injury infrastructure. Most work is done on 'soft' money and there is active concern 
that funding and staffing for non-road injury prevention will fall below effective threshold levels.

The need for programs on adolescent injury - particularly on self harm; inadequate processes for maintaining standards and improving product safety; reaching beyond well educated populations and means to address high aboriginal injury rates; and the need for continuing effort even in successful areas (for example, about half of children killed or injuries in road accidents are still unrestrained), are injury matters under discussion.

The good news is that safety regulations are being implemented with subsequent impact on death and injury (pool fencing, smoke alarms, domestic hot water), there has been success in involving groups outside public health (for example, plumbers in campaigns on controlling domestic hot water). There is increasing effort on sports injury prevention, the public profile of injury is rising, and significant interest was generated in preparing for the international conference.

\section{NEW ZEALAND}

There has been success in implementing a range of regulations related to child injury prevention - domestic swimming pool fencing, compulsory use of bicycle helmets and motor vehicle restraints, the temperature of hot water, the use of safety glass in new buildings, and wider use of child resistant packaging for medication. There has been non-regulatory success also such as agreement with supermarkets for extended use of harnesses in shopping trolleys.

New programs and pilots are being implemented pilots for child injury reduction using the safe communities approach, a 'safe routes to school' pedestrian program, a collaborative intersectoral plan in a major region, planning for a national child safety week, and inclusion of injury in national curriculum in schools.

The challenges include developing and supporting injury reduction for Maori communities; reaching multicultural populations; addressing youth suicide and risk taking; implementing safety features in existing housing; dealing with product safety; and overcoming the current poor infrastructure and the lack of secure finances.

\section{Comment}

The breadth of these activities is truly impressive. Some areas of the world have sophisticated injury control activities, while others are just beginning. Unfortunately, we have no report on activities from South America. I hope that this can be remedied soon. A common theme throughout these reports is the effort being given to placing child and adolescent injury control activities on the agenda of governments everywhere. Collection of accurate data, passage of legislation to protect children and adolescents, and funding of injury control activities are the responsibilities of government to its citizens. However, the reports during the international conference in Melbourne, the articles in this journal, and the success stories from around the world demonstrate that we can all make a difference in reducing morbidity and mortality from injuries.

FREDERICK P RIVARA

Chair, ISCAIP

IAN ROBERTS

DAVID BASS

R KRISHNAN

MYINT MYINT THEIN SUSAN GALLAGHER
IAN SCOTT

Correspondence to Professor Rivara at:

Harborview Injury Prevention and Research Center,

Box 359960, 325 Ninth Avenue,

Seattle,

WA 98104, USA

(Phone: +1206521 1530, fax +1 206521 1562, e-mail: fpr@u.washington.edu)

1 World Health Organization. World health statistics annual. Geneva: WHO, 1989-91.

2 World Bank. World development report. New York: Oxford University Press, 1995

3 Baker SP, Fingerhut LA, Higgins L, Chen L-H, Brauer ER. Injury to children and teenagers. State-by-state mortality facts. Baltimore, MD: Johns Hopkins Center for Injury Research and Policy, Feb 1996. 